\title{
O Lugar: Duas Acepções Geográficas ${ }^{1}$
}

\author{
Adriana Filgueira Leite \\ Mestranda do PPGG/UFRJ - Laboratório de Geo-Hidroecologia - UFRJ
}

\section{Introdução}

O conceito de lugar tem sido alvo das diversas interpretações ao longo do tempo e entre os mais variados campos do conhecimento. Uma das mais antigas definições de lugar foi apresentada por Aristóteles na sua obra intitulada Física. Para ele o lugar seria o limite que circunda o corpo. Alguns séculos adiante, Descartes através de sua obra Princípios Filosóficos busca um aprimoramento do conceito introduzido por Aristóteles afirmando que além de delimitar o corpo, o lugar deveria ser também definido em relação a posição de outros corpos (Ribeiro, 1996). Na Geografia particularmente, a expressão lugar constitui-se em um dos seus conceitos-chave. Apesar das amplas reflexões já realizadas a cerca do seu significado, é possível afirmar que este é o conceito menos desenvolvido neste campo do saber. Porém é possível identificar duas acepções principais, sendo estas consideradas em dois de seus eixos epistemológicos: o da Geografia Humanística e o da Dialética Marxista. Embora ambas as correntes possuam fundamentações filosóficas diferenciadas, têm em comum o fato de terem surgido como reações ao positivismo então vigente o qual permite a descrição da natureza a partir de leis e teorias assim como a dissociação Homem-meio.

\section{Lugar e Experiência}

No campo da Geografia Humanística este conceito surge no âmbito da sua consolidação no início da década de 70 . Sua linha de pensamento caracteriza-se principalmente pela valorização das relações de afetividade desenvolvidas pelos indivíduos em relação ao seu ambiente. Para tanto houve um apelo às filosofias do significado - fenomenologia, existencialismo, idealismo e hermenêutica - que em essên-

${ }^{1}$ Gostaria de agradecer ao professor e amigo João Baptista Ferreira de Mello do Departamento de Geografia da Universidade do Estado do Rio de Janeiro (UERJ), não só pelas sugestões bibliográficas como principalmente pelo grande apoio prestado. 
cia encontram na subjetividade humana as interpretações para suas atitudes perante o mundo (Mello, 1990; Holzer, 1993; Holzer, 1997). Dentre os grandes expoentes afins a essa acepção destacam-se Edward Relph, Yi-Fu Tuan, Anne Buttimer e J. N. Entrikin. No Brasil destacam-se os trabalhos de Mello no sentido da compreensão das percepções do carioca frente ao processo de urbanização da cidade do Rio de Janeiro (a partir das músicas do repertório popular) e de Holzer, porém este mais direcionado a reflexões teórico-metodológicas dentro desta perspectiva de estudos.

Para os seguidores da corrente humanística, o lugar é principalmente um produto da experiência humana: “(...) lugar significa muito mais que o sentido geográfico de localização. Não se refere a objetos e atributos das localizações, mas à tipos de experiência e envolvimento com o mundo, a necessidade de raízes e segurança” (Relph, 1979). Ou ainda, "lugar é um centro de significados construído pela experiência” (Tuan, 1975). Trata-se na realidade de referenciais afetivos os quais desenvolvemos ao longo de nossas vidas a partir da convivência com o lugar e com o outro. Eles são carregados de sensações emotivas principalmente porque nos sentimos seguros e protegidos (Mello, 1990); ele tanto nos transmite boas lembranças quanto a sensação de lar (Tuan, 1975; Buttimer, 1985a). Nas palavras de Buttimer (1985b, p. 228), "lugar é o somatório das dimensões simbólicas, emocionais, culturais, políticas e biológicas”.

No entanto, essa relação de afetividade que os indivíduos desenvolvem com o lugar só ocorre em virtude de estes só se voltarem para ele munidos de interesses prédeterminados, ou melhor, dotados de uma intencionalidade. Como afirma Relph (1979), os lugares só adquirem identidade e significado através da intenção humana e da relação existente entre aquelas intenções e os atributos objetivos do lugar, ou seja, o cenário físico e as atividades ali desenvolvidas. Nas palavras de Tuan (1975), o lugar "é criado pelos seres humanos para os propósitos humanos”. Tuan (1975), afirma ainda que há uma estreita relação entre experiência e tempo, na medida em que o senso de lugar raramente é adquirido pelo simples ato de passarmos por ele. Para tanto seria necessário um longo tempo de contato com o mesmo, onde então houvesse um profundo envolvimento. No entanto, seria possível a um indivíduo apaixonar-se a primeira vista por um lugar tal qual por uma pessoa (Tuan, 1983). Em contraste, uma pessoa pode ter vivido durante toda a sua vida em determinado local e a sua relação com ele ser completamente irreal, sem nenhum enraizamento. Um bom exemplo deste tipo de experiência refere-se a um estudo desenvolvido por Godkin (1985) junto a alcoólatras 
em processo de recuperação. Ele cita o caso de Doris, uma mulher que fora acolhida em um orfanato aos quatro anos de idade por ocasião do internato de sua mãe em uma instituição mental. Doris não conseguiu sentir-se parte do orfanato o qual mostrava-se para ela como um lugar inseguro e ameaçador. Em seu relato ela diz: "o assoalho era de madeira dura; enormes habitações sem móveis, frias, sem intimidade... grandes dormitórios. Eram habitações grandes, muito grandes, onde me sentia pequena, só...”. Tal relato vai diretamente ao encontro do que afirma Tuan (1975): "se leva tempo conhecer um lugar, a própria passagem do tempo não garante um senso de lugar. Se a experiência leva tempo, a própria passagem do tempo não garante a experiência”.

Há porém uma crítica no que diz respeito a consideração das variáveis tempo e processo dentro da perspectiva humanística. De acordo com Cosgrove (1978), elas são praticamente ausentes nesta abordagem, principalmente nas obras de Relph e Tuan. Para ele, tal dificuldade seria uma resultante direta de uma inabilidade implícita no próprio método analítico empregado pela Geografia Humanística em explicar os fenômenos do lugar e da paisagem da mesma forma como esta se refere à consciência humana. Cosgrove afirma que se por um lado o método fenomenológico fornece consideráveis contribuições a respeito dos significados que os lugares e as paisagens têm para nós, particularmente como indivíduos, por outro, ao aplicar-se a uma experiência coletiva, suas suposições são demasiado idealistas e até ingênuas. Ao abstrair "mentes", “almas”, "espíritos”, “idéias” e "intenções” de modo a representá-los como entidades independentes, recai-se sobre as interpretações filosóficas tradicionais utilizadas pelo positivismo, de caráter determinístico. Embora admita-se uma relação dialética entre a mente e o mundo, a ênfase do método acaba privilegiando as abstrações da mente. Para Cosgrove, esta abstração seria, no entanto, falsa pois nem estaria de acordo com nossa experiência no mundo, e nem nos permitira a possibilidade de entender a razão para coisas, pois nossas atitudes e intenções, são também influenciadas por outros fatores tais como as relações de produção.

A experiência do lugar manifestaria-se também em diferentes escalas. Nas palavras de Buttimer (1985b, p. 178), “cada pessoa está rodeada por camadas concêntricas de espaço vivido, da sala para o lar, para a vizinhança, cidade, região e para a nação". Na realidade, tais entidades são todos lugares experienciados diretamente. O lar é onde a vida começa e termina; é o principal referencial de existência da espécie humana na medida em que este é a forma concreta do abrigo, da proteção contra as intempéries 
e outros perigos potenciais. O lar é o pivô de uma rotina diária. Vamos a todos os tipos de lugares (escola, trabalho, igreja, discoteca, etc.) mas sempre retornamos ao lar, ou lugares semelhantes (abrigos, acampamentos, hotéis, etc.). Na percepção de Tuan (1975), “o que a lareira, a loja de doces na esquina, a cidade, e o Estado-Nação têm em comum? Eles são todos centros de significado para os indivíduos e grupos”. A cidade e a nação embora não sejam conhecidos integralmente por cada um dos indivíduos, são ambos símbolos da fraternidade Homem-lugar os quais constituiríam-se na realidade, em um único ser. Segundo Frémont (1980, p. 205), a maioria das nações conta com um forte sentimento de unidade interna o qual seria propiciado principalmente pela comunhão do idioma e da cultura (poderíamos incluir em alguns casos a religião, a exemplo dos países mulçumanos). Deste modo, os homens não viveriam "sobre” ou na "nação". Os jogos esportivos, assim como os avanços tecnológicos, dentre outros eventos de mesmo caráter são sempre ocasiões em que este sentimento patriótico ou em menor escala, de bairrismo afloram (Mello, 1990). Para Pocock (1981, p. 337), o que há na realidade, é uma relação simbiótica entre homem e meio ambiente. Neste sentido, lugares devem ser considerados como pessoas e as pessoas como lugares.

Os lugares normalmente não são dotados de limites reconhecíveis no mundo concreto. Isto ocorre porque sendo uma construção subjetiva e ao mesmo tempo tão incorporada as práticas do cotidiano que as próprias pessoas envolvidas com o lugar não o percebem como tal. Este senso de valor só manifesta-se na consciência quando há uma ameaça ao lugar, como a demolição de um monumento considerado importante, ou quando há uma reivindicação comum como a visita periódica de um carro do "fumacê”. Assim, ao contrário das regiões delimitadas para fins de planejamento, plenamente reconhecíveis em mapas e cartas topográficas, através de símbolos e toponímias, a maioria dos lugares não são nomeados. Dar nome a um lugar é dar seu explícito reconhecimento, isto é, reconhecê-lo conscientemente ao nível da verbalização (Tuan, 1975), fato este que não ocorre na realidade. Dentro desta perspectiva, Bachelard (1978) afirma que "é a semente que faz a maçã, e ainda assim a miniatura da semente é maior do que a grandeza da maçã”. Ou seja, apesar da intensidade das experiências vividas à nível do país, da cidade, do bairro, ou da rua, se fossem representados cartograficamente, tais lugares seriam menores que sementes, mas ainda assim germinariam afeição.

No entanto, tais relações de identidade não mapeáveis, nem sempre são respeitadas ao nível dos interesses governamentais. Buttimer (1985a, p. 230) cita o 
caso de Glasgow, um dos bairros de Londres submetido aos programas de reforma urbana do Reino Unido após a 2 ${ }^{\mathrm{a}}$ Guerra Mundial. As escavadoras respeitaram apenas os limites invisíveis ou lugares sagrados; hoje, vários anos depois, tabernas e igrejas permanecem como mesas em uma paisagem arrasada, ilhadas de sua clientela cujas casas antigamente as rodeavam. No Brasil essas práticas não são raras e desde o início do século vêm tornando-se até bastante comuns. Um exemplo clássico foi o processo de destruição da Praça XI, conhecida como o berço do samba e da boemia da cidade do Rio de Janeiro até meados da década de 40. Este lugar era um importante referencial tanto para a comunidade quanto para artistas e malandros, principalmente durante o Carnaval. Com a abertura da Avenida Presidente Vargas ocorrida entre 1941 e 1944, a Praça XI foi parcialmente destruída, perdendo completamente o seu caráter cultural. A paisagem do bairro foi alterada substancialmente, empurrando seus moradores para outras localidades (Lima, 1995, p. 53).

No entender de Buttimer (1985a, p. 231), tais procedimentos resultariam de uma dificuldade do observador (planejador) em identificar as relações históricas embutidas nas formas. Para ela, a linguagem utilizada para descrever as perspectivas dos residentes sobre o lugar é ainda, de modo geral, a linguagem de um mundo Newtoniano - gente, atividades e coisas contidas no lugar - enquanto que a linguagem utilizada para planificar os horizontes econômicos e tecnológicos do lugar está profundamente influenciada pelas concepções Einsteinianas do espaço topológicos, do tempo e do processo.

Considerando os diferentes graus de compreensão da realidade apresentados pelos indivíduos, Relph (1976) desenvolveu duas classes de percepção dialética Homemmeio: insider (ótica do habitante do lugar) e outsider (ótica de um habitante externo ao lugar). Em cada uma dessas classes haveriam níveis intermediários de percepção, variando entre o mais enraizado e o mais desenraizado.

Uma outra caracterização das relações Homem-meio foi realizada por Mello (1990), baseada principalmente nas obras de Tuan (Espaço e Lugar, 1983) e de Relph (Place and Placelessness, 1976). Assim, ele identifica três principais categorias; o lugar, conforme já discutido, é recortado afetivamente, e emerge da experiência sendo assim um "mundo ordenado e com significado" (Tuan, 1983, p. 65). O lugar é fechado, íntimo e humanizado (Tuan, 1983, p. 61); já o espaço seria qualquer porção da superfície terrestre, ampla, desconhecida, temida ou rejeitada e provocaria a sensação de medo, 
sendo totalmente desprovido de valores e de qualquer ligação afetiva. Neste contexto, o lugar está contido no espaço. No entanto, as experiências nos locais de habitação, trabalho, divertimento, estudo e dos fluxos transformariam os espaços em lugares. $\mathrm{O}$ último conceito seria o de "deslugar" (placelessness), um neologismo criado por Relph para designar as formas estandartizadas, repetidas e com uniformidade de seqüência, como os conjuntos habitacionais e algumas lanchonetes fast food distribuídas ao longo das estradas. Este conceito tem sido alvo de muitas discussões no âmbito da Geografia Humanística, pois questiona-se se as pessoas que o experienciam realmente consideramno monótono e artificial. Neste sentido, Relph também introduz uma discussão a respeito de atitudes autênticas e inautênticas em relação ao lugar. As atitudes autênticas seriam aquelas em que o indivíduo teria plena consciência do teor ideológico embutido naquelas formas. Por outro lado, uma atitude inautêntica caracterizaria uma visão alienada do lugar e a relação Homem-mundo vivido não seria plena. Exemplos dessa experiência seriam as relações mantidas entre os indivíduos e as formas universalizadas dos shopping-centers e das lanchonetes McDonnald`s (conhecidas no mundo inteiro), assim como os locais com o estilo da Disneylândia (que simula uma perpetuação da infância) ou do complexo turístico de Cancun, cujas mercadorias nada têm a ver com a cultura local. Eyles (1989, p. 109), no entanto, faz uma crítica a essa percepção que sugere que as tendências homogeneizantes do mundo moderno resultam para a grande massa das pessoas, em uma atitude "inautêntica” em relação ao lugar e num estado de “deslugar”. Para ele, há um profundo descrédito no que se refere a capacidade que as pessoas têm em criar identidade com os lugares apesar de serem subúrbios (ou formas homogeneizadas). Ao mesmo tempo, nem sempre o motivo que leva alguém a residir em tais lugares são dependentes da sua vontade. As condições materiais são na maioria das vezes os principais determinantes.

Mello (1990) refere-se ainda à existência de lugares míticos e concebidos. Os primeiros seriam aqueles lugares que apesar de nunca terem sido experienciados concretamente assumem para nós a imagem do paraíso, alimentando os nossos mais profundos desejos em manter com ele um contato direto (a exemplo da atração exercida por lugares como o Caribe e a cidade de Veneza sobre cidadãos do mundo inteiro). Já os lugares concebidos, apesar de também não serem experienciados fisicamente, seriam locais mais próximos, com os quais entraríamos em contato via mecanismos de imprensa ou por relatos de indivíduos já conhecedores dos mesmos. 


\section{Lugar e Singularidade}

A outra acepção de lugar diz respeito a sua compreensão enquanto expressão geográfica da singularidade, descentrada, universalista, objetiva, associada ao positivismo ou ao Marxismo. Trata-se na realidade de uma visão na qual o lugar é considerado tanto como produto de uma dinâmica que é única, ou seja, resultante de características históricas e culturais intrínsecas ao seu processo de formação, quanto como uma expressão da globalidade. Neste sentido, o lugar se apresentaria como “o ponto de articulação entre a mundialidade em constituição e o local, enquanto especificidade concreta e enquanto momento" (Carlos, 1996, p. 16).

A origem desta percepção encontra-se intimamente relacionada ao processo de expansão do modo capitalista de produção que através de uma ampla rede de fluxos (de transportes, de informação e de mercadorias), conseguiu incorporar progressivamente todos os pontos da superfície do planeta, inclusive aqueles considerados como os mais remotos. A “descoberta” de "novos” territórios a partir das grandes navegações propiciou a ampliação dos conhecimentos a respeito do globo, indicando simultaneamente que este era finito e potencialmente apreensível. De acordo com Harvey (1992, p. 221) “a acumulação de riqueza, de poder e de capital passou a ter um vínculo com o conhecimento personalizado do espaço e o domínio individual dele. Do mesmo modo, todos os lugares ficaram vulneráveis a influência direta do mundo mais amplo graças ao comércio, á competição intraterritorial, a ação militar, ao influxo de novas mercadorias, ao ouro e a prata etc". Ele acrescenta ainda que "em virtude do desenvolvimento gradativo dos processos que lhe davam forma, a revolução das concepções de espaço e de tempo se manifestou lentamente”. Na medida em que a dimensão espaço foi se tornando cada vez mais finita, a dimensão tempo foi aos poucos sendo reduzida. Este foi um reflexo direto do aprimoramento das técnicas (aumento da produção em um tempo menor) e das redes de transporte e comunicação.

Como este processo completou-se apenas neste século, com níveis de universalidade e desenvolvimento nunca antes imaginados, somente agora tornou-se possível teorizar-se a respeito de categorias que fossem igualmente universalizantes e de aplicação geral, como é (dentro desta percepção) o conceito de lugar (Santos, 1988, p. 32). Na medida em que as contradições internas constituem-se na principal razão de existência do Capitalismo, o lugar, segundo este ponto de vista, seria também um reflexo 
desta ambigüidade, e logo das dualidades centro/periferia, geral/pontual, globalização(homogeneização)/fragmentação.

O processo de homogeneização/fragmentação tem suas bases fundamentadas na Europa de finais do século XVIII, mais precisamente na França pós-Revolução. A necessidade de um novo modelo de gestão do território que fosse eficiente em propiciar o bem-estar social e este, por sua vez, dentro dos princípios da igualdade, encontrou na homogeneização do espaço o único meio de exercer sobre ele o controle, e logo de alcançar tais objetivos (Harvey, 1992, p. 231). Houve neste momento um grande desenvolvimento da cartografia matemática que contrariamente às práticas comuns à Idade Média, passou a projetar nos mapas um espaço abstrato, homogêneo e universal em suas qualidades, propiciando assim um quadro de pensamento e de ação estável e apreensível (Harvey, 1992, p. 221). Esta concepção da realidade encontrou vários adeptos entre arquitetos, engenheiros, administradores e proprietários de terra. Na iminência da eclosão de outras concepções do espaço e do tempo então coexistentes (sagradas, profanas, simbólicas, pessoais, etc), sentiu-se a necessidade de alguma medida que consolidasse o uso do espaço dentro dos moldes desejados (homogêneo, abstrato e universal); o meio encontrado para tal foi a instituição da propriedade privada da terra e da compra e venda do espaço como mercadoria, em outras palavras, a fragmentação (Harvey, 1992, p. 221).

De fato, como afirma Lefebvre (1974, apud Harvey, 1992), uma das formas de alcançar-se a homogeneização do espaço, é justamente através de sua fragmentação em parcelas "livremente alienáveis de propriedade privada que podem ser compradas e comercializadas à vontade no mercado". Na realidade, o que houve de fato foi o deslocamento de uma função que antes restringia-se aos mecanismos estatais e logo, aos limites do Estado-Nação. A partir de então o uso da terra passa a ser gerido pelo mercado, o qual conforme já discutido, tornou-se ao longo dos anos, cada vez mais global. Assim é que o processo de homogeneização (globalização) pressupunha simultaneamente o da fragmentação.

Com o passar do tempo essa estrutura complexizou-se. O mercado internacional passou a ser a "mola mestra" das economias nacionais. Havendo simultaneamente, um aumento progressivo da especialização das funções exercidas por cada área. Os países que haviam dado origem ao capitalismo tornaram-se as grandes potências mundiais 
passando a determinar através de suas empresas (grandes coorporações), a divisão internacional do trabalho. Enquanto estas contituíram-se nas áreas centrais (centro do poder político e econômico), as áreas recém “descobertas” então colônias, assumiram a posição de periferia. Sua principal função era a de fornecer matérias-primas e consumir os produtos industrializados. Assim, a ordem mundial característica a este momento constava já de uma estrutura dual (centro-periferia) onde os países centrais (metrópoles) além de assumirem a função de organizadores, transformavam as matérias-primas que eram produzidas pelas economias agrário-exportadoras (colônias).

Ao mesmo tempo em que há uma estrutura global onde cada um possui uma função determinada, características locais também passam a ser incorporadas e reestruturadas em função de um contexto maior e homogeneizante - o mercado internacional. Um claro exemplo desta prática foi a apropriação da encomienda na colônia espanhola do México. A encomienda era um tributo pago pelos camponeses do então Império Asteca ao seu rei, e constava da doação mensal de toda a colheita agrícola referente a um dia inteiro de trabalho. Quando os espanhóis tornaram-se os colonizadores, tanto destruíram o Império como escravizaram seus descendentes, tornando a encomienda um tributo obrigatório e diário. Em uma fase posterior, este também é o caso da apropriação de relações de trabalho pré-capitalistas (arrendamento, parceria), introduzidas no Brasil no período colonial e ainda vigentes. Esta prática constitui-se atualmente em uma grande fonte de lucros para os donos do grande capital (no caso, redes de supermercados e empresas da indústria alimentícia) na medida em que obtém os produtos agrícolas a baixíssimos preços sem praticamente nenhuma despesa com a produção.

É dentro deste contexto que o lugar surge tanto como uma expressão do processo de homogeneização do espaço imposta pela dinâmica econômica global, quanto uma expressão da singularidade, na medida em que cada lugar exerce uma função imposta pela divisão internacional do trabalho. Nas palavras de Carlos (1996, p. 17) “a realidade do mundo moderno reproduz-se em diferentes níveis, no lugar encontramos as mesmas determinações da totalidade sem com isso eliminar-se as particularidades, pois cada sociedade produz seu espaço, determina os ritmos da vida, os modos de apropriação expressando sua função social, seus projetos e desejos”. O lugar surge como produto de uma ambigüidade que se estende a todas as relações sociais que envolvem o homem e o meio - é o singular (o fragmento) e é também o global (universal) que o determinam. 
Para Milton Santos (1988, p. 34) "quanto mais os lugares se mundializam, mais se tornam singulares e específicos, isto é, únicos”. Esta seria uma resultante direta da "especialização desenfreada dos elementos do espaço - homens, firmas, instituições, meio ambiente", assim como da "dissociação sempre crescente dos processos e subprocessos necessários a uma maior acumulação de capital, da multiplicação das ações que fazem do espaço um campo de forças multidirecionais e multicomplexas (...)”.

Carlos (1996, p. 20) acrescenta ainda uma dimensão histórica na concepção do lugar. Esta diz respeito a prática cotidiana, ou seja, às concepções que surgem do plano do vivido, e neste sentido é bastante similar a percepção humanística. Para ela, pensar o lugar "significa pensar a história particular (de cada lugar), se desenvolvendo, ou melhor, se realizando em função de uma cultura/tradição/língua/hábitos que lhe são próprios, construídos ao longo da história e o que vem de fora, isto é, que se vai construindo e se impondo como conseqüência do processo de constituição do mundial”.

Apesar das peculiaridades inerentes a cada lugar, estes encontram-se profundamente interligados. De acordo com Santos (1988, p. 34), ao mesmo tempo em que a singularidade garante configurações únicas, os lugares estão em interação, graças a atuação das forças motrizes do modo de acumulação hegemonicamente universal (o capitalismo). Para ele, o que se verifica na atualidade é o que preescreve a Lei da Interconexão Universal proposta por Marquit (1981). De acordo com esta lei “todas as coisas estão ligadas às demais por uma infinidade de conexões”. De fato esta é uma realidade do mundo moderno, onde uma intensa rede de fluxos (de mercadorias, informações, etc.) marca a conexão entre lugares. Tais redes caracterizam-se por apresentar uma estrutura extremamente complexa, organizada de acordo com a especialidade de funções e segundo uma hierarquia de atividades (Corrêa, 1997, p. 108). Esta complexidade está também na essência das relações centro-periferia, na medida em que é um dos mecanismos pelos quais tais relações são perpetuadas e as diferenças aprofundadas. As cidades globais (sedes das grandes corporações) na qualidade de epicentros de numerosas dessas redes, têm promovido a organização do espaço de modo a torná-lo cada vez mais fragmentado e globalizado (Corrêa, 1997, p. 108), o que pressupõe o acirramento das diferenças entre dominadores e dominados. Para Carlos (1996, p. 33), o lugar pode ser definido a partir desses entrelaçamentos impostos pela divisão espacial do trabalho posto que é articulado e determinado pela totalidade espacial. 
A intensa especialização das funções, aliada ao aprimoramento tecnológico tem causado sérios impactos ao nível do lugar, principalmente no que diz respeito à liberação de enormes contingentes de mão-de-obra. Num âmbito mundial pode-se dizer que este é um reflexo tanto da globalização quanto da fragmentação. Trata-se de um fenômeno extremamente dinâmico e na maioria das vezes o operário não consegue acompanhar esse ritmo visto que exige do trabalhador um nível de qualificação cada vez mais elevado e num curto espaço de tempo. A repercussão global é o desemprego em massa e o trabalho temporário via contratação (prestação de serviços) em empresas especializadas.

A nível local, cada lugar vai reagir de uma maneira própria, a partir de condições pré-existentes. Pode-se dizer também, neste sentido, que o lugar com suas características locais e globais, é um reflexo da compressão espaço-tempo - se de um lado as redes de fluxos diminuem as distâncias espaciais, por outro, a velocidade em que se processam tais fluxos tende a quase extingüir a dimensão tempo. Para Harvey (1992, p. 190) “o progresso implica a conquista do espaço, a derrubada de todas as barreiras espaciais e a aniquilação última do espaço através do tempo”. Essa aniquilação, no entanto, é contraditória na medida em que "o espaço só pode ser conquistado por meio da produção do espaço” (Harvey, 1992, p. 234). Isso porque o espaço tanto é o palco onde desenvolvem-se as relações sociais, quanto é o local de assentamento dos meios de vida, transportes e comunicação. Assim, torna-se necessária não apenas "a produção de um espaço específico, fixo e imóvel para promover a 'aniquilação do espaço por intermédio do tempo’, como também investimento de longo prazo, de retorno lento (fábricas automatizadas, robôs, etc.), para acelerar o tempo de giro da massa de capitais” (Harvey, 1992, p. 234). Esta dinâmica ganha expressividade no espaço através dos processos de “destruição criativa”. Tais processos, aliados aos constantes efeitos das redes de fluxos e logo da compressão espaço-tempo, trazem para o lugar um efeito que o define enquanto expressão da singularidade: a sua constante reestruturação como uma resultante das constantes transformações históricas. Por fim, isso se refletiria nas palavras proferidas por Santos (1988, p. 35) - “já não se pode falar de contradição entre uniqueness e globalidade. Ambos se completam e se explicam mutuamente. O lugar é um ponto do mundo onde se realizam algumas das possibilidades deste último. O lugar é parte do mundo e desempenha um papel em sua história (...)”. 


\section{Referências}

BACHELARD, G. 1978. A Poética do Espaço. In: OS PENSADORES, São Paulo, Abril Cultural, p. 181-354.

BUTTIMER, A 1985a. Aprendendo o dinamismo do mundo vivido. In: PERSPECTIVAS DA GEOGRAFIA. Antônio Carlos Christofoletti (org.). São Paulo, Difel, p. 165-193.

BUTTIMER, A. 1985b. Hogar, Campo de Movimiento y sentido del Lugar. In: TEORIA Y MÉTODO EN LA GEOGRAFIA ANGLOSAJONA. Maria Dolores Garcia Ramón (org.), Barcelona, Ariel, p. 227-241.

CARLOS, A F. A 1996. O Lugar no/do Mundo. São Paulo. Hucitec. 150 p.

CORRÊA, R. L. 1997. Dimensões de análise das redes geográficas. In: TRAJETÓRIAS GEOGRÁFICAS. Roberto Lobato Corrêa. Rio de Janeiro. Bertrand Brasil, p. 107-118.

COSGROVE, D. E. 1978. Place, Landscape, and the Dialectics of cultural Geography. Canadian Geographer, 22 (1): 1978.

EYLES, J. 1989. The Geography of everyday life. In: HORIZONS IN HUMAN GEOGRAPHY, Derek Gregory and Rex Walford (eds.), Houndmills, Macmillan Education, p. 102-117.

FRÉMONT, A 1980. A região, Espaço Vivido. Coimbra, Almadina, 275p.

GODKIN, M. A. 1985. Identidad y Lugar: Aplicaciones Clínicas Basadas en los Naciones de Arraigo y Desarrolo. In: TEORÍAY METODO EN LA GEOGRAFIA HUMANA ANGLOSAJONA, María Dolores García Ramón (org.), Barcelona, Ariel, p. 242-253.

HARVEY, D. 1992. Condição Pós-Moderna. São Paulo. Loyola. 349p.

HOLZER, W. 1993. A Geografia Humanista anglo-saxônica - de suas origens aos anos 90. R. Bras. Geog., 55 (1/4): 109-146.

HOLZER, W. 1997. A Geografia Humanista: uma revisão. Espaço e Cultura, 3: 8-19.

LIMA, E. F. W. 1995. Avenida Presidente Vargas: uma drástica cirurgia. Biblioteca Carioca. Rio de Janeiro. Secretaria Municipal de Cultura. 143p.

MELLO, J. B. F. 1990. Geografia Humanística: a perspectiva da experiência vivida e uma crítica radical ao positivismo. R. Bras. Geog., 52 (4): 91-115.

POCOCK, D. C. D. 1981. Place and the Novelist. Transactions of the British Geographers, New Series 6, p. 337-347.

RELPH, E. C. 1976. Place and Placelessness. London. Pion. 156p.

RELPH, E. C. 1979. As Bases Fenomenológicas da Geografia. Geografia, 4 (7): 1-25.

RIBEIRO, W. C. 1993. Do Lugar ao Mundo ou o Mundo no Lugar? Terra Livre AGB, 11-12: 237-242.

SANTOS, M. 1988. Metamorfose do Espaço Habitado. São Paulo. Hucitec.124p.

TUAN, Yi-Fu. 1975. Place: an experiential perspective. Geographical Review, 65 (2): 151-165.

TUAN, Yi-Fu. 1983. Espaço e Lugar. São Paulo.Difel..250p. 